MONOGRÁFICO: TECHNOHERITAGE 2019. 4TH INTERNATIONAL CONGRESS SCIENCE

AND TECHNOLOGY FOR THE CONSERVATION OF CULTURAL HERITAGE. SELECCIÓN DE CONTRIBUCIONES / TECHNOHERITAGE 2019. A SELECTION OF CONTRIBUTIONS

\title{
Un modelo HBIM aplicado a la lectura diacrónica de la arquitectura: la capilla de los Tocino (s. XV) de Jerez de la Frontera*
}

\section{A digital model applied to the diachronic reading of architecture: The Tocino chapel (15 ${ }^{\text {th }}$ Century) of Jerez de la Frontera}

\author{
José María Guerrero Vega ${ }^{1}$, Francisco Pinto Puerto², Gregorio Mora Vicente ${ }^{3}$ \\ Universidad de Sevilla. Grupo PAIDI-HUM 799 Estrategias de Conocimiento Patrimonial
}

\section{RESUMEN}

Se expone una experiencia de aplicación de modelos digitales HBIM a la intervención arqueológica y arquitectónica sobre la capilla de los Tocino de la iglesia de San Juan de los Caballeros de Jerez de la Frontera. El objeto de esta es verificar las posibilidades de una herramienta dinámica capaz de incorporar y gestionar datos y permitir visualizaciones complejas de la secuencia estratigráfica obtenida de los trabajos previos y paralelos a la intervención. De esta forma, la propia obra se entiende como una fase más, que queda asociada a las anteriores, lo que permite explicar y justificar las propias acciones de intervención. Entre las principales conclusiones, cabría destacar la formación de un modelo único que aglutina la totalidad de la información generada, abierto a la incorporación de nueva información y capaz de generar imágenes que facilitan la comprensión espacial del objeto.
\end{abstract}

Palabras clave: HBIM; patrimonio; gestión de información; restauración monumental; arqueología de la arquitectura; gótico-mudéjar; marcas de cantero.

\begin{abstract}
An experience of the application of digital HBIM models to the archaeological and architectural intervention on the Tocino chapel of the church of San Juan de los Caballeros at Jerez de la Frontera is expounded. Its purpose is to verify the possibilities of a dynamic tool that can incorporate and manage data, and allow complex visualizations, of the stratigraphic sequence obtained from previous and parallel to the intervention work. Thus, the restoration work is seen as another phase, which is associated with previous work, which helps to explain and justify their own intervention actions. Among the main conclusions, we should highlight the formation of a unique model that brings together all the information generated, open to the incorporation of new information and capable of generating images that facilitate the spatial understanding of the object.
\end{abstract}

Key words: HBIM; heritage; information management; monumental restoration; archaeology and architecture; Gothic-Mudejar; stonecutter marks.

Recibido: 03-02-2020. Aceptado: 20-04-2020. Publicado: 13-04-2021

Cómo citar este artículo / Citation

Guerrero Vega, J. M., Pinto Puerto, F. y Mora G. 2021: "Un modelo HBIM aplicado a la lectura diacrónica de la arquitectura: la capilla de los Tocino (s. XV) de Jerez de la Frontera", Arqueología de la Arquitectura, 18: e112. https://doi.org/10.3989/arq.arqt.2021.004

Copyright: (c) CSIC, 2021. (c) UPV/EHU Press, 2021. Este es un artículo de acceso abierto distribuido bajo los términos de la licencia de uso y distribución Creative Commons Reconocimiento 4.0 Internacional (CC BY 4.0).

\footnotetext{
El contenido de este artículo tiene como base los trabajos desarrollados en el marco del Proyecto TUTSOSMOD. Tutela Sostenible del Patrimonio Cultural a través de Modelos Digitales BIM y SIG. Contribución al conocimiento e innovación social (HAR2016-78113-R) del Ministerio de Ciencia, Innovación y Universidades. http://grupo.us.es/tutsosmodhum/

jmgv@us.es / ORCID iD: https://orcid.org/0000-0003-3164-328X

fspp@us.es / ORCID iD: https://orcid.org/0000-0003-4608-6818

gmora@us.es / ORCID iD: https://orcid.org/0000-0003-2784-2438
} 


\section{INTRODUCCIÓN}

\subsection{Objetivos}

La presente aportación tiene como objetivo explorar las posibilidades que ofrecen los modelos HBIM (Heritage Building Information Modeling) para el registro y gestión de información relativa a los procesos de lectura cronológica de edificios históricos, mediante la integración de enfoques interdisciplinares durante su conocimiento e intervención, así como sus consecuencias en los procesos de tutela del patrimonio arquitectónico. Utilizando un caso concreto, se pretendía crear un espacio de trabajo donde quedara recogida y relacionada la información recabada en estos procesos y el conocimiento generado, evitando la generación de una versión hiperrealista de la realidad tratada.

El uso de medios digitales en el ámbito del patrimonio está suponiendo un cambio de paradigma en la relación tradicional entre realidad y representación gráfica tradicional, que debemos enmarcar dentro de lo que viene a denominarse "humanidades digitales". Así, comenzamos a resolver, entre otras, la difícil inclusión de la dimensión temporal en la representación de las formas, tan necesarias en el análisis arqueológico y arquitectónico, y en general entre los agentes interesados en el conocimiento, la gestión y la difusión de la arquitectura histórica.

Se presenta el modelado de la capilla funeraria de los Tocino, conocida tradicionalmente como capilla de la Jura, anexa a la iglesia de San Juan de los Caballeros de Jerez de la Frontera para obtener un modelo HBIM. En su última restauración, desarrollada entre los años 2015 y 2016, se plantearon procesos y estrategias de trabajo interdisciplinares antes, durante y después de su intervención. En esta última etapa se planteó la construcción de un modelo digital que contuviera la información generada durante todo este proceso, permitiera su trazabilidad, y describiera las principales fases de su historia arquitectónica. Dada la limitada extensión de esta aportación, además de su construcción, abordaremos otras dos fases, la reforma inconclusa documentada a finales del siglo XIX, y la reciente intervención de restauración. Por otra parte, se incluye también la gestión de la información relativa a las marcas de cantero descubiertas en el proceso.

\subsection{Antecedentes}

A nivel general, crear un modelo supone la selección intencionada de aspectos de la realidad a la que se refiere bajo algún motivo o finalidad, en función de la eta- pa de la tutela patrimonial en la que nos encontremos. Cada selección supone una toma de decisión sobre lo que se representa y lo que se deja de representar (González 2018). En este sentido, el uso de modelos digitales BIM en el patrimonio arquitectónico ha supuesto un fructífero campo de experimentación internacional en los últimos años, dando origen a un extenso repertorio de casos de aplicación, con objetivos y métodos de trabajo muy variados (Logothetis, Delinasiou y Stylianidis 2015; Dore y Murphy 2017; Pocobelli et al. 2018a). Destacan entre estos, aquellas líneas de investigación relacionadas con la conservación preventiva, abarcando aspectos como el análisis y monitorización estructural (Dore et al. 2015; Banfi et al. 2017), la creación de bibliotecas de elementos constructivos (Oreni et al. 2013), la caracterización e información superficial (Pocobelli et al. 2018b; Angulo y Castellano 2020), o la conexión con bases de datos externas (Quattrini, Pierdicca y Morbidoni 2017). Además, se han desarrollado algunas investigaciones que exploran la aplicación de estos modelos a la lectura arqueológica de conjuntos edilicios (Utrero, Murillo y Martín-Talaverano 2016; Brusaporci et al. 2018).

A pesar del desarrollo de propuestas para establecer protocolos en este campo (Jordan et al. 2018), aún no existen normas y sistemas homologados al margen del uso convencional del BIM, procedente del ámbito de la ingeniería para modelizar todos los aspectos constructivos y espaciales de edificios de nueva planta. A nivel nacional, desde la experiencia ejemplar llevada a cabo en la restauración y activación cultural de la catedral de Santa María de Vitoria (Azkarate et al. 2001), hasta el reciente intento de normalizar el campo de trabajo de lo que viene a denominarse HBIM por un amplio colectivo de investigadores (Armisen 2018), nos encontramos en un campo de debate y experimentación abierto que se nutre poco a poco de experiencias y logros parciales.

El caso seleccionado, la capilla de los Tocino, es un espacio funerario formado en la primera década del siglo XV, anexo a la cabecera de la iglesia de San Juan de los Caballeros (Fig. 1). Como resumen, cabría decir que se trata de un espacio de planta cuadrada, con extensiones laterales en forma de tres arcosolios y arco de acceso, adaptado a los dos primeros contrafuertes del presbiterio en el evangelio del templo. Está cubierto por una bóveda octogonal estrellada de nervadura, resolviendo la transición entre ambas figuras con trompas angulares (Mora y Guerrero 2015). El promotor de la obra fue Andrés Martínez Tocino, y se ha podido do- 


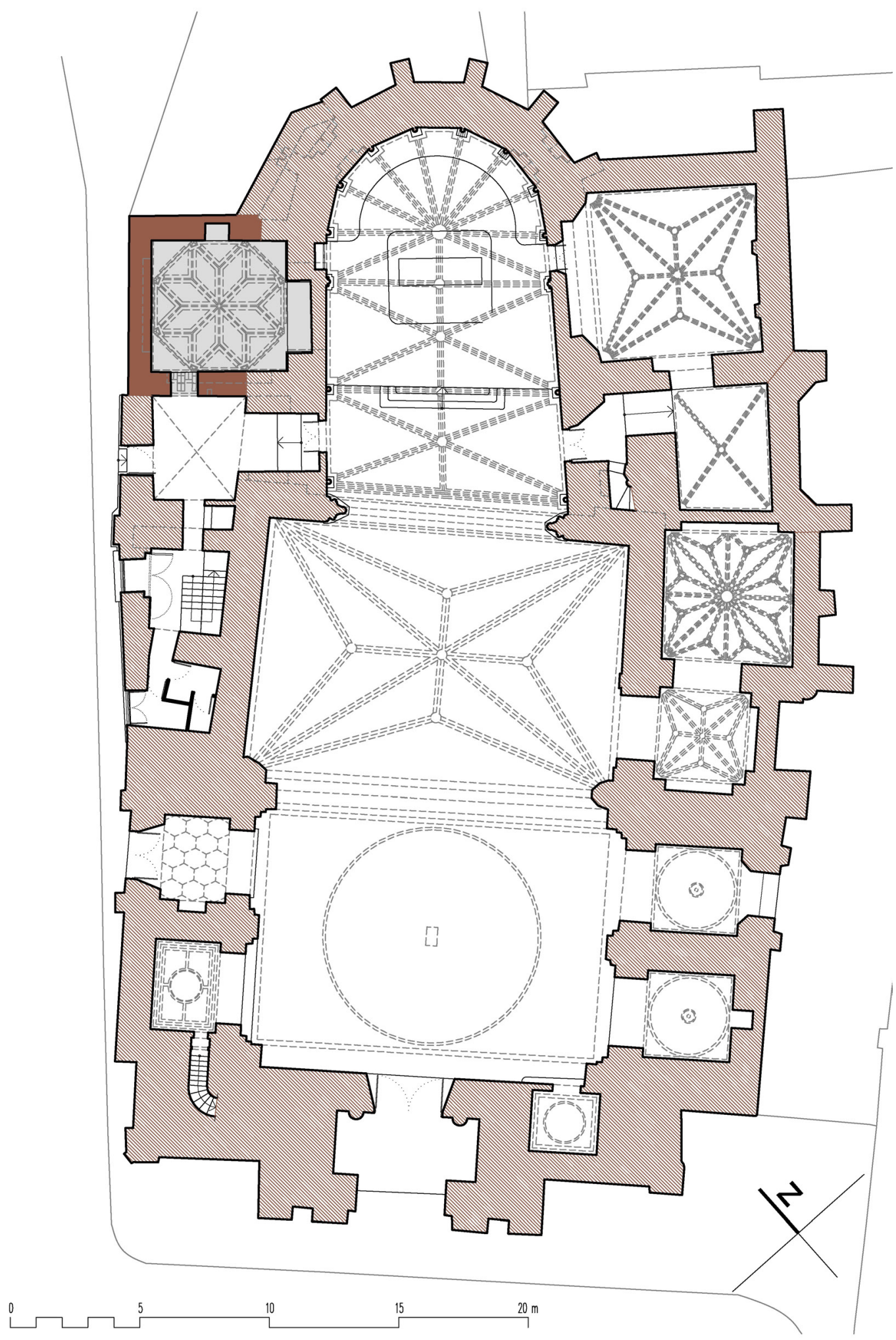

Figura 1. Planta de la iglesia de San Juan de los Caballeros (en gris se destaca la capilla de los Tocino). Estado actual. Fuente: Elaboración propia. 
cumentar que el proyecto se ejecutaba en el año 1404 bajo la responsabilidad de los maestros Fernán García y Diego Fernández (Jácome y Antón 2007). Su nota más característica es la convivencia de elementos de tradición mudéjar y gótica; destacando respectivamente el arcosolio del altar y la bóveda (López 2014: 73). Antes de la intervención era una sala de almacenaje en pésimo estado de conservación, en la que destacaban las huellas de un proceso de restauración inacabado a finales del XIX, donde la comunicación con la iglesia se había perdido y funcionaba como dependencia secundaria.

La metodología de trabajo diseñada en la última intervención combinaba arqueología y análisis arquitectónico no circunscritos al espacio intervenido, sino relacionados con la parroquia y la secuencia histórica de la ciudad (Guerrero et al. 2019). Estos trabajos generaron una importante cantidad de datos que se expusieron siguiendo los cauces habituales: informes, publicaciones, participación en congresos, conferencias locales... con un importante papel de la representación gráfica convencional que con dificultad ha permitido la visualización de los cambios de esta pequeña estancia, fundamentalmente planimetrías y perspectivas a partir del levantamiento gráfico que se realizó antes y después de la intervención.

En cuanto a los resultados generales, a partir de la intervención arqueológica se establecieron tres niveles cronológicos que partían de la fundación de la iglesia (segunda mitad del siglo XIV), la construcción de la capilla en 1404, y un largo episodio de mantenimiento y postrera degeneración, en el que destaca por su impronta la reforma inacabada de finales del siglo XIX (Álvarez, Guerrero y Romero 2003: 106-111). También se catalogaron los tipos de aparejo de cada etapa vinculándose a sus procesos constructivos, encuentros entre fábricas y elementos singulares como arcos, capiteles, molduras, revestimientos, marcas de cantero, etc. (Guerrero, Pinto y Mora 2019).

Se planteó la necesidad de componer una herramienta capaz de sumar el grueso de la documentación, tanto la precedente, como la acumulada durante el proceso de intervención arqueológica y arquitectónica, apoyado en la metodología BIM aplicada al Patrimonio (HBIM). Como primera aproximación se elaboró un prototipo a partir de cuatro ejes de conocimiento patrimonial: arquitectura, historia, arqueología y restauración. El resultado fue un modelo que, en primera instancia, permitía acceder a la secuencia de las etapas cronológicas detectadas en el conjunto del templo, representadas tridimensionalmente a un nivel medio de detalle volumétrico (Guerrero, Mora y Pinto 2020). Se trataba de superar la fórmula de representación tradicional alcanzando un estadio capaz de contener globalmente todos los datos, con posibilidad de completarlo $\mathrm{y}$ actualizarlo conforme se modifique el conocimiento sobre el edificio, y que, así mismo, permitiera concretar la visualización de situaciones seleccionadas por el espectador; es decir, un lugar en el que se pudiera trabajar de lo general a lo particular, y viceversa (Castellano y Pinto 2019).

\section{Planteamiento Metodológico DEL MODELADO HBIM}

El modelo se ha elaborado a partir de herramientas gráficas digitales a las que se aplica una sistemática de trabajo que debe adaptarse y hacerse compatible a las diversas estrategias disciplinares que se dedican al conocimiento y gestión del patrimonio. Entendemos con esto que no debe ser "la máquina", entendida como conjunto de herramientas y rutinas, la que condicione los procesos de conocimiento. Al contrario, deben ser estos últimos los que determinen el ámbito de trabajo y planteen las exigencias a estas "máquinas", lo que no evita que se produzcan adaptaciones en ambas direcciones. Por otro lado, consideramos que el uso de herramientas, ya sean las convencionales basadas en recursos analógicos o las digitales, no es inocuo a los procesos de conocimiento. No lo ha sido a lo largo de la historia, y no lo será ahora, por lo que es necesario mantener el uso de estos recursos sometidos a una constante revisión, pues el ámbito de lo digital está inundando todos los ámbitos disciplinares de falsas soluciones universales y automatismos (Pinto y Guerrero 2013). Por esta razón, esta aportación se produce después de hacer un exhaustivo recorrido sobre el caso de estudio que se ha expuesto de forma muy resumida en el apartado anterior y en extenso en las publicaciones citadas. En el trabajo que ahora exponemos, el modelo surge en un momento posterior al proceso de análisis arqueológico y la intervención arquitectónica, pero bien pudiera haberse iniciado con anterioridad al mismo e ir creciendo y completándose con él.

En esta experiencia queda pendiente la gestión de la entrada y salida de datos de aquellos agentes que son ajenos al uso de la herramienta, pero que pueden ser posibles usuarios de esta, permitiendo así la incorporación 


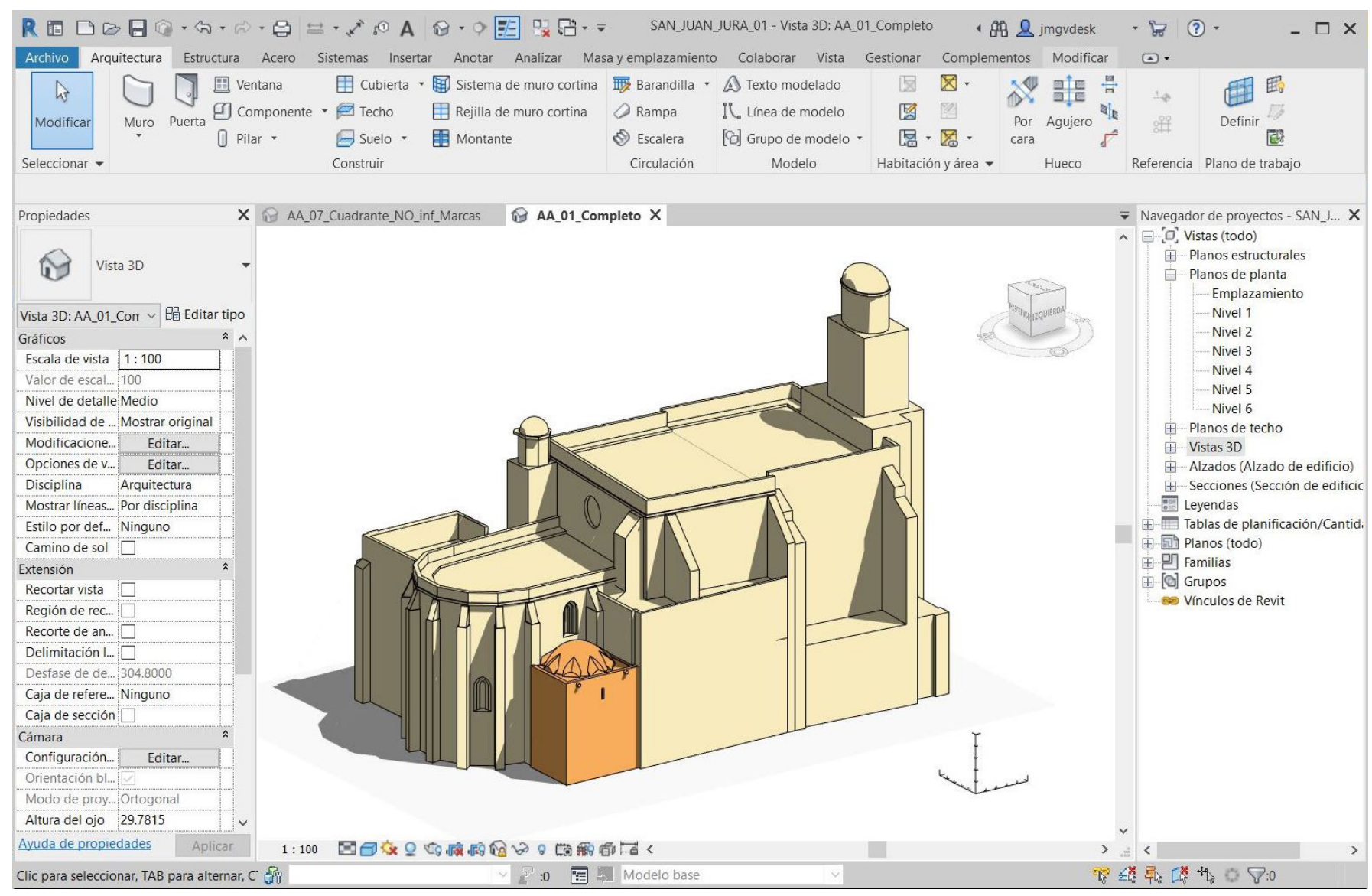

Figura 2. Captura de pantalla del programa Autodesk Revit. Modelo completo de la iglesia parroquial de San Juan de los Caballeros (en naranja se destaca la capilla de los Tocino). Estado actual. Fuente: Elaboración propia.

efectiva de estos modelos a los procesos de trabajo interdisciplinares.

\section{PROCESO DE TRABAJO}

El punto de partida ha sido el modelo del templo completo desarrollado con anterioridad, donde a nivel básico y con geometrías muy simplificadas, se pretendía representar cada uno de los cuerpos y espacios principales que se han ido incorporando a la fábrica. La asignación a cada uno de estos de una fase cronológica permitía visualizar de forma dinámica la evolución del edificio a lo largo de su historia (Guerrero, Mora y Pinto 2020). Este modelo, desarrollado con Autodesk Revit 2020, se ha ampliado ahora con mayor detalle en el ámbito de la capilla de los Tocino (Fig. 2), que se ha creado como un modelo federado respecto al modelo genérico. Se aprovecha de este modo su carácter abierto -susceptible de ser modificado-, una de las ventajas esenciales de los modelos digitales frente a las herramientas de re- presentación tradicional, con la posibilidad de corregir, completar, enriquecer estos y generar variadas visualizaciones de imágenes y datos. De esta forma, se podrían añadir a este modelo genérico del templo otras partes más desarrolladas a medida que se obtenga una información más precisa, estando todos vinculados entre sí.

En base a los objetivos marcados en cada caso, tanto en el modelo genérico inicial como en el posterior desarrollo de la capilla se ha optado por distintos grados de simplificación de forma que en el primero de ellos se modelaron masas tridimensionales de entidades arquitectónicas completas, mientras que en la capilla se han modelado los elementos constructivos que delimitan el espacio interior del oratorio. En este primer nivel, la precisión geométrica, aunque apoyada en una toma de puntos de control con estación laser de topografía, queda en un segundo plano, priorizando una aproximación global al conjunto a modelar (Castellano y Pinto 2019). En el caso de la capilla, el modelado tridimensional se ha realizado a partir del levantamiento gráfico elaborado como parte de los trabajos previos a la intervención donde se 
combinó la toma de datos mediante estación de topografía, distanciómetro láser y herramientas tradicionales. El resultado de este levantamiento fue un conjunto de dibujos de vistas de planta, alzados y secciones. Este levantamiento inicial se completó con fotogrametría digital convergente en la fase de excavaciones arqueológicas. A partir de esta información se modelaron los elementos constructivos de la capilla (Fig. 3).

Dadas las dificultades para adecuar los distintos elementos predefinidos de los que disponen este tipo de plataformas de trabajo, concebidos para la obra de nueva planta, se ha optado por modelar de forma individualizada la práctica totalidad de los distintos elementos constructivos (muros, cornisas, bóvedas, cubierta, hue$\cos . .$.$) , sin recurrir a biblioteca de objetos predefinidos.$ La presencia generalizada de elementos singulares en los edificios históricos se ve acentuada aún más en el campo de la arqueología donde el paso del tiempo suele dar como resultado fragmentos de los elementos originales con geometrías irregulares (Scianna et al. 2015).

A cada uno de los elementos modelados se le asignó una de las categorías en las que el programa informático clasifica los elementos constructivos - muros, suelos, cubiertas...-, y en base a esta codificación se estable- ció una serie de propiedades disponibles para cada tipo de estos elementos que describían, de forma general, su configuración material y su cronología, aunque el número y naturaleza de las posibles propiedades a asignar a cada elemento podrían ampliarse en función de otros criterios de análisis o futuras necesidades. Los seguidos a la hora de diferenciar en la edificación los elementos tridimensionales modelados se han basado, por una parte, en su categorización constructiva-arquitectónica, y, por otra parte, en las unidades estratigráficas identificadas en la lectura arqueológica. La superposición de estas dos clasificaciones determina el número mínimo de elementos individuales a los que se les ha podido asignar propiedades diferenciadas. En este sentido, tal y como permite el programa informático, cada elemento constructivo modelado puede ser dividido en fragmentos más pequeños -que el programa denomina "piezas"- a los que se le pueden asignar propiedades y valores diferentes del original (Fig. 4).

En relación con el aspecto temporal, a partir de la lectura estratigráfica y la documentación histórica, la evolución del edificio se dividió en una serie de fases sucesivas. Tal y como permite la aplicación, a cada uno de los objetos modelados $-\mathrm{o}$ a cada una de sus partes- se le

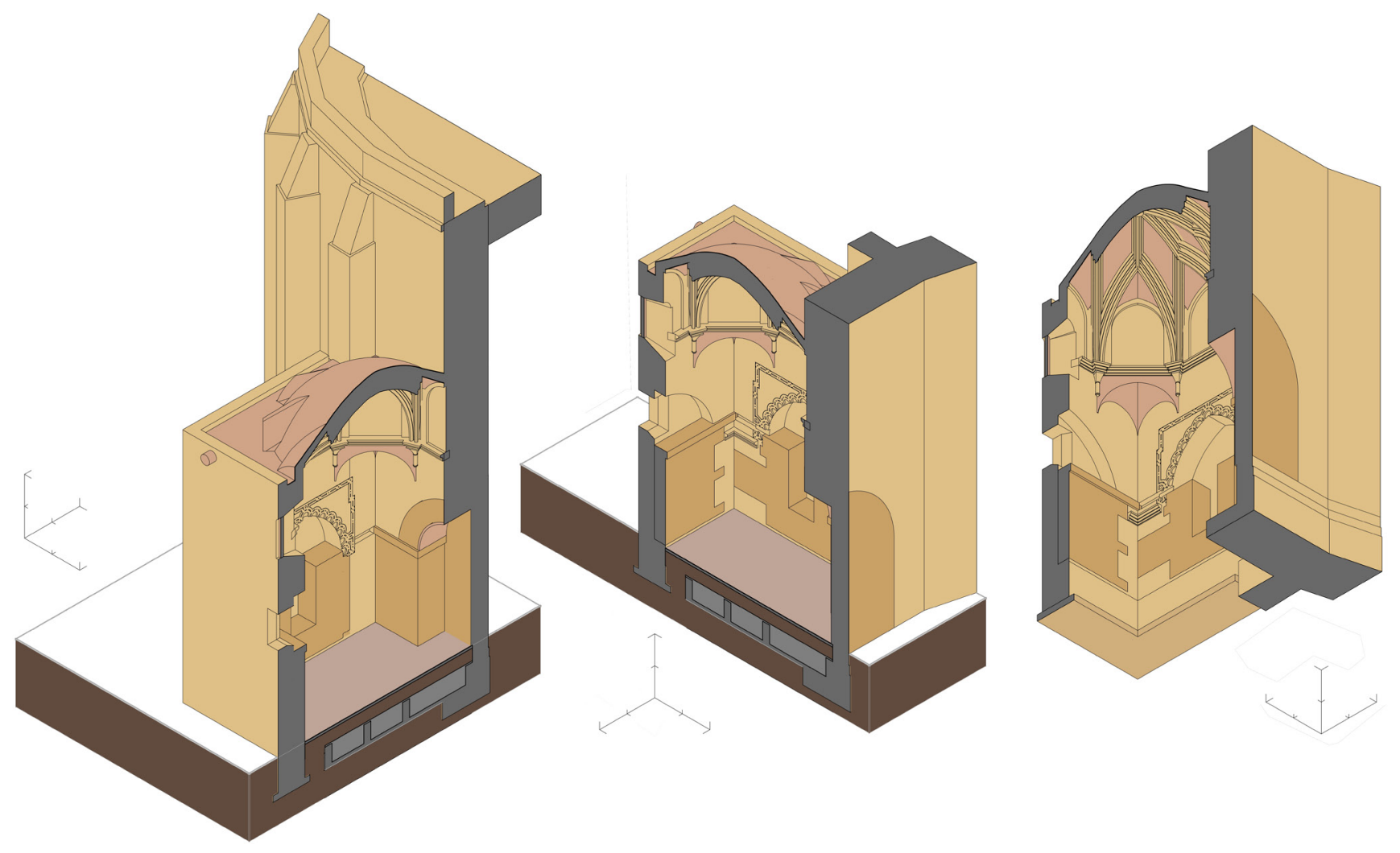

Figura 3. Vistas isométricas de la capilla seccionada. Estado previo a la última intervención. Fuente: Elaboración propia. 

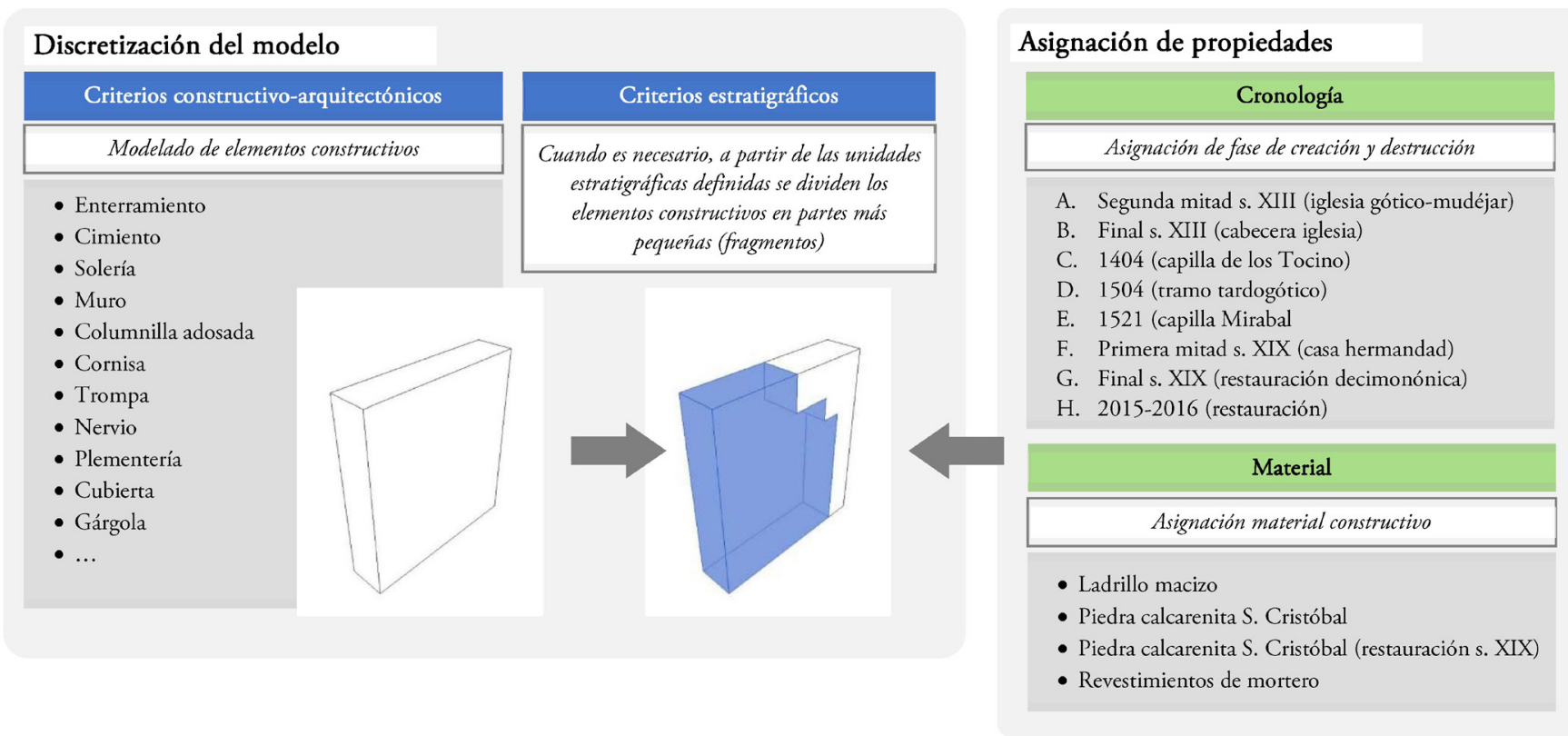

Figura 4. Esquema de trabajo: discretización del modelo y asignación de propiedades. Fuente: Elaboración propia.

asignó una de estas fases para su construcción o creación y otra de destrucción. De esta manera, se pudieron establecer aquellas unidades que estaban presentes en cada una de las fases, reconstruyendo la secuencia temporal, incorporando al modelo la sucesión de transformaciones a lo largo del tiempo. El modelo permite, así, reflejar el carácter diacrónico de las construcciones históricas.

A partir del modelo tridimensional pueden obtenerse, mediante vistas fácilmente configurables distintas proyecciones diédricas convencionales, así como axonometrías y perspectivas. Además, en base a la información introducida pueden configurarse diferentes consultas gráficas en las que la representación de cada uno de los elementos se determine en función de las propiedades seleccionadas. De esta forma, cabe resaltar la ventaja de poder visualizar el modelo de la capilla en cualquiera de las etapas evolutivas consideradas, pudiéndose generar imágenes con un claro potencial comunicativo, o individualizar elementos concretos según los valores de alguna de sus propiedades (Fig. 5).

El nivel de detalle alcanzado puede incrementarse a partir de futuras necesidades y además es posible vincular al modelo información adicional como por ejemplo nubes de puntos generados en levantamientos posteriores. Se constata así la posibilidad de constituir repositorios de la información asociada a cada elemento, que se irá acumulando en el tiempo, y facilitar su gestión en el futuro.

\section{RESULTADOS}

Podemos cifrar los resultados en relación con el conocimiento obtenido durante el proceso de intervención y la utilidad de su modelado. En concreto podemos centrarnos en tres aspectos: la identificación y registro de marcas de cantero, las evidencias de la intervención del siglo XIX, y la última intervención de restauración. En sí mismo, cada uno de estos tiene posibilidades descriptivas particulares y suman en el conocimiento general de capilla e iglesia.

En cuanto a los grabados de cantería, dan idea de un organigrama complejo de la obra en la que intervienen varios agentes. Se trata de símbolos esgrafiados en la superficie de la piedra realizados tras el proceso de tallado de los sillares para identificar al cantero que había realizado el trabajo. Durante la intervención identificamos un buen número de marcas en los paramentos, tanto en el correspondiente a la cabecera del templo, como en los tres muros de cierre de la capilla. Los signos, ubicados desde la cimentación a la cubierta, permitieron apoyar la hipótesis planteada ya con anterioridad (López 2014: 73), de que toda la obra pertenecía a un solo impulso constructivo, frente a otras hipótesis que proponían que la bóveda era resultado de una profunda reforma tardía. El uso del modelo permite obtener una vista detallada en la que podemos diferenciar materiales y señalar los signos. Su presencia supera un papel descriptivo y se con- 


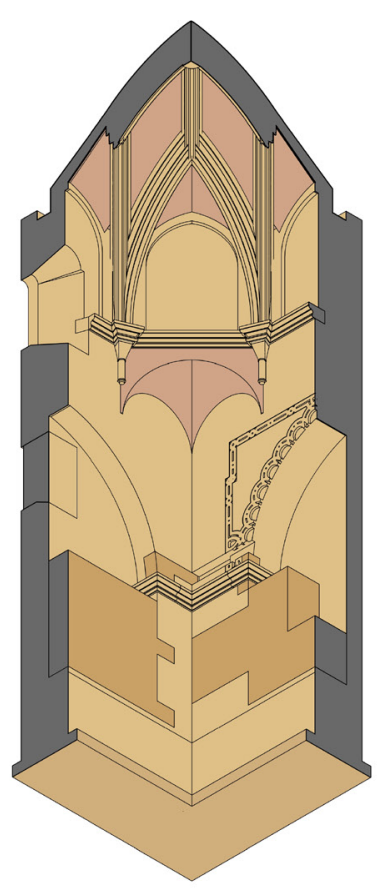

A

PIEDRA CALCARENITA (S. Cristóbal)

PIEDRA CALCARENITA RESTAURACIÓN (S. Cristóbal)

LADRILLO

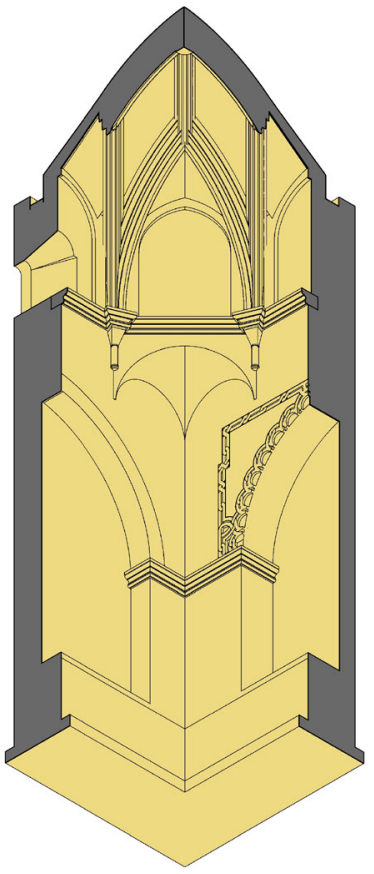

B

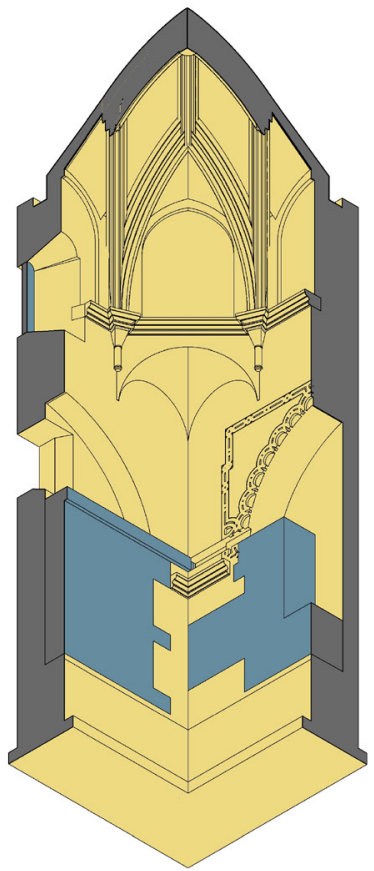

C

CONSTRUCCIÓN DE LA CAPILLA (1404)

RESTAURACIÓN (Finales S. XIX)

RESTAURACIÓN (2015-2016)

Figura 5. Sección cuadrante septentrional de la capilla. A) Materiales; B) Construcción de la capilla (1404); C) Restauración (Finales s. XIX); D) Restauración (2015-2016). Fuente: Elaboración propia.

vierte en fósil director para la comprensión cronológica de la capilla. En este caso se han modelado las marcas, asignando a cada ejemplar una signatura de identificación, así como el modelo de marca utilizado, lo cual permite obtener imágenes donde se identifiquen algunos de los modelos empleados (Guerrero 2019). Cada una de las marcas se representa con un símbolo que queda asociado a la superficie de los paramentos con su ubicación real, permitiendo superar los mecanismos de representación bidimensional de las secciones, pudiendo editarlas y visualizarlas según distintos criterios, en otros tipos de vista (Fig. 6).

Respecto a la restauración decimonónica, contamos con información a propósito de su autor y cronología. El arquitecto Rafael Esteve se encargó de ella sobre 1890, aunque es difícil precisar el momento exacto porque trabajó en toda la iglesia entre 1880 y 1896 . Nuestro trabajo aportó una secuencia clara de estas actuaciones, diferenciando entre tareas de consolidación y renovación en estilo, aunque estas últimas no pudieron completarse. De nuevo el modelo permite acercarse a esta actuación a través del registro de los elementos modificados y originales salvados por su carácter inconcluso. Seleccionamos una vista en la que se aprecian ordenadas cronológicamente las huellas materiales de su actuación: en cimentación vació las criptas del sepulcro y creó un potente recalce de hormigón para contrarrestar los empujes de la nave central, verdadera causa del mal estado de la capilla (Fig. 7) (Guerrero, Pinto y Mora 2019). A nivel emergente reforzó los arcosolios originales para aumentar la masa de los muros uniéndolos a los antiguos mediante enjarjes que necesitaron de la sustracción de piezas originales, dispuso de nuevas cornisas rectangulares y sustituyó el acceso original por un arco de medio punto también de piedra (Fig. 8). Ahí quedó detenida su intervención: el arco no se llevó a abrir, ni las molduras a tallar, la presencia de los refuerzos en bruto daba a la estancia una imagen notablemente inacabada. El modelo contiene en un mismo espacio todas las circunstancias materiales de sustracción y adición de piezas, a las que se asigna una cronología específica, pudiendo generar visualizaciones en las que elegimos los objetos a presen- 
tar y en las que modificamos la codificación gráfica de cada elemento: transparencias, elección de ángulos de visión conforme a sistemas de representación convencionales. Cada una de estas visualizaciones supone una decisión intencionada de lo que se quiere ver y de qué manera, dependiendo del usuario y sus necesidades, en este caso, destinada a facilitar su comprensión.

Por último, la secuencia evolutiva de la capilla determinó la propuesta de la última intervención de restauración arquitectónica, que apostó por mantener visibles en el edificio dos estratos temporales superpuestos a través de la modificación mínima de cada uno de ellos y el tratamiento superficial común de cada etapa con objeto de facilitar la percepción simultánea de ambas. Esto su-

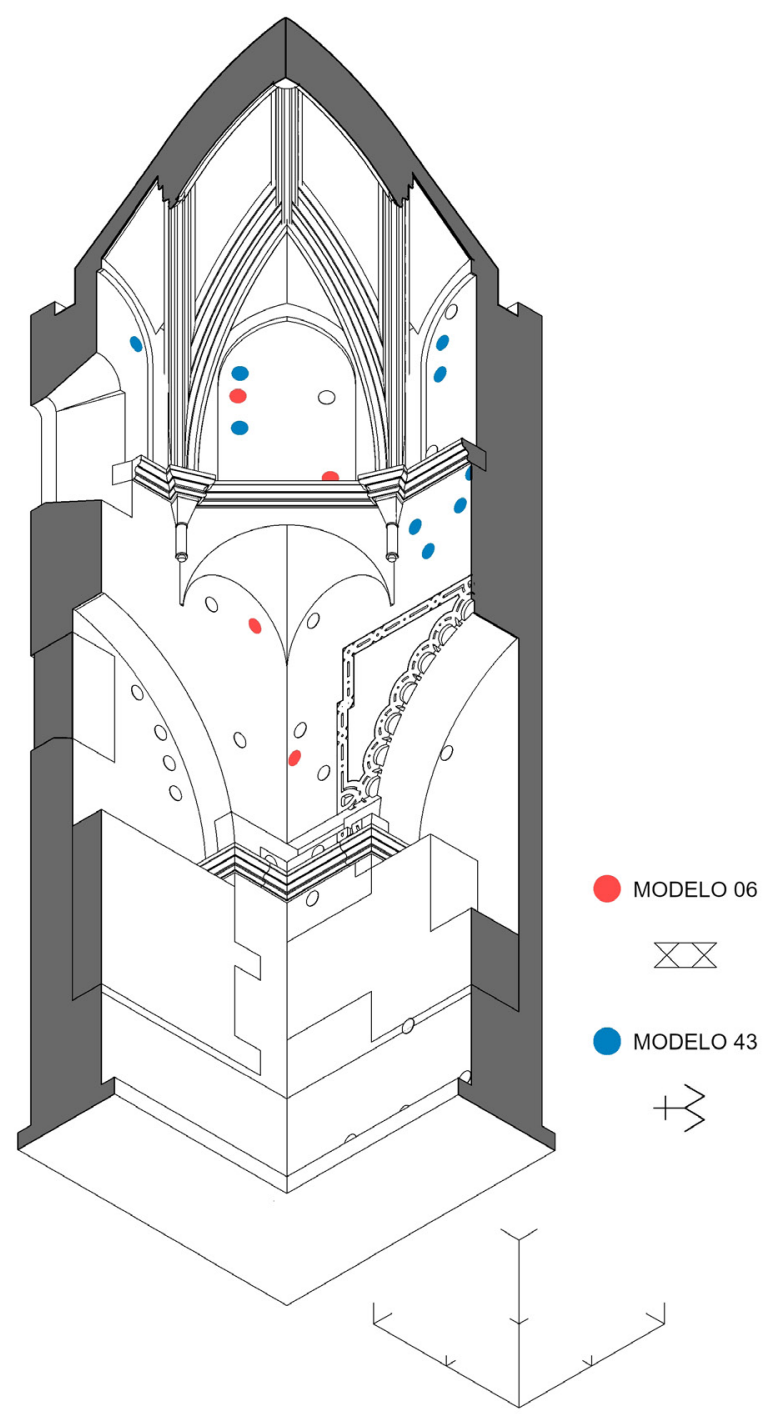

Figura 6. Sección cuadrante septentrional de la capilla. Registro de marcas de cantero. Fuente: Elaboración propia.
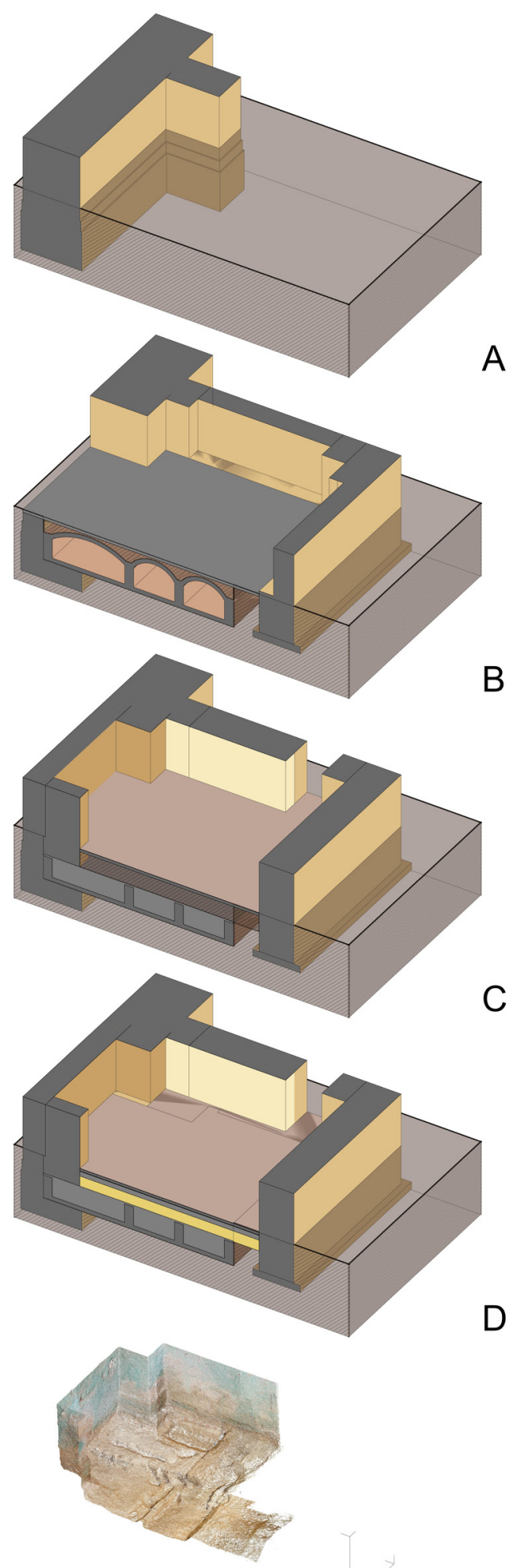

D

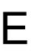

Figura 7. Mitad suroeste de la capilla. Transformaciones del subsuelo: A) Construcción de la cabecera del templo (Finales s. XIV); B) Construcción de la capilla (1404); C) Restauración (Finales del s. XIX); D) Restauración (2015-2016); E) Nube de puntos de la fotogrametría realizada durante la fase de excavación arqueológica (2015). Fuente: Elaboración propia. 


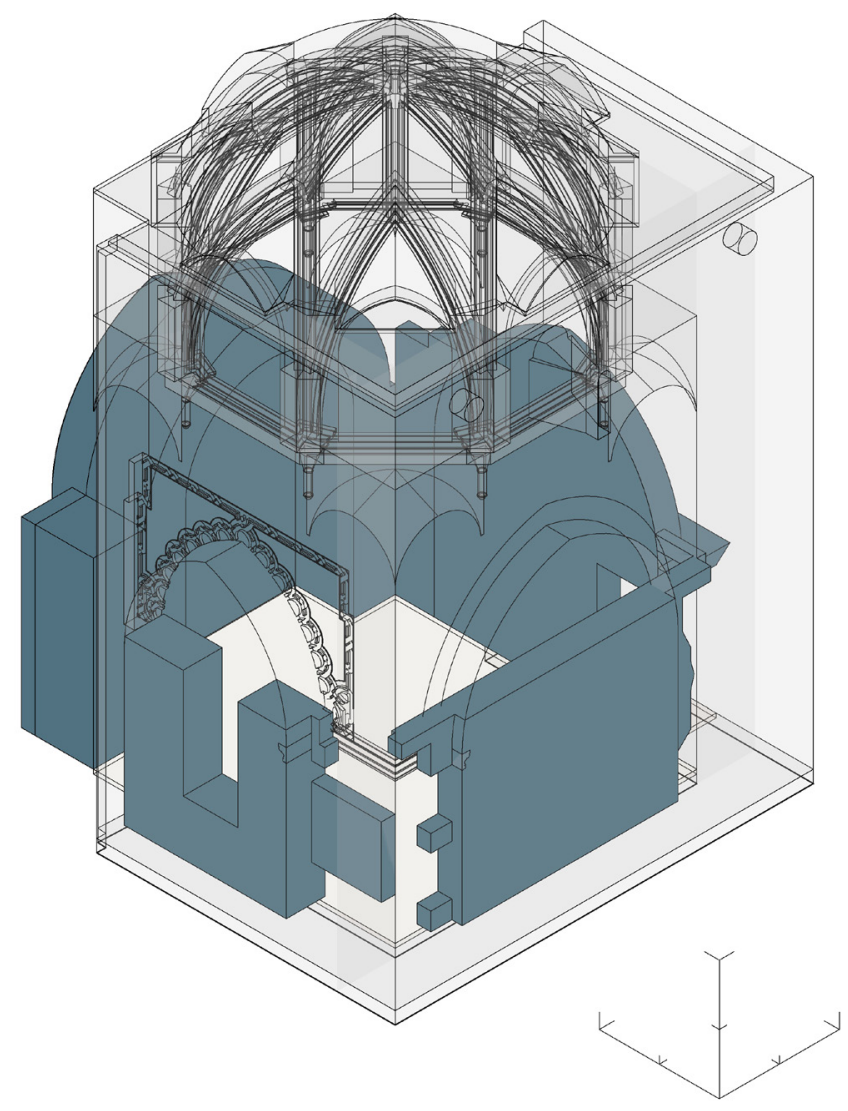

Figura 8. Elementos de refuerzo incorporados en la restauración de finales del siglo XIX. Fuente: Elaboración propia.

puso desmontar parte de la intervención decimonónica para recuperar la percepción de los elementos mínimos imprescindibles para reconstruir visualmente el espacio original medieval (Fig. 9). Esta decisión requirió tratar las lagunas provocadas por las pérdidas de revestimiento de los plementos de la bóveda, diferenciar visualmente los refuerzos del s. XIX dejando vista la piedra que añadieron entonces, y en los paramentos originales se repusieron los revestimientos desaparecidos. En este caso, el modelo permite dejar constancia del estado de la intervención decimonónica, los elementos eliminados entonces y los añadidos en nuestra intervención, a la vez que mostrar el resultado final de la intervención, que no es más que otra capa histórica de su estratigrafía.

\section{CONCLUSIONES}

Nos parece oportuno señalar cómo la finalidad, prestaciones previstas y recursos disponibles condicionaron tanto el planteamiento inicial como el proceso de cons-

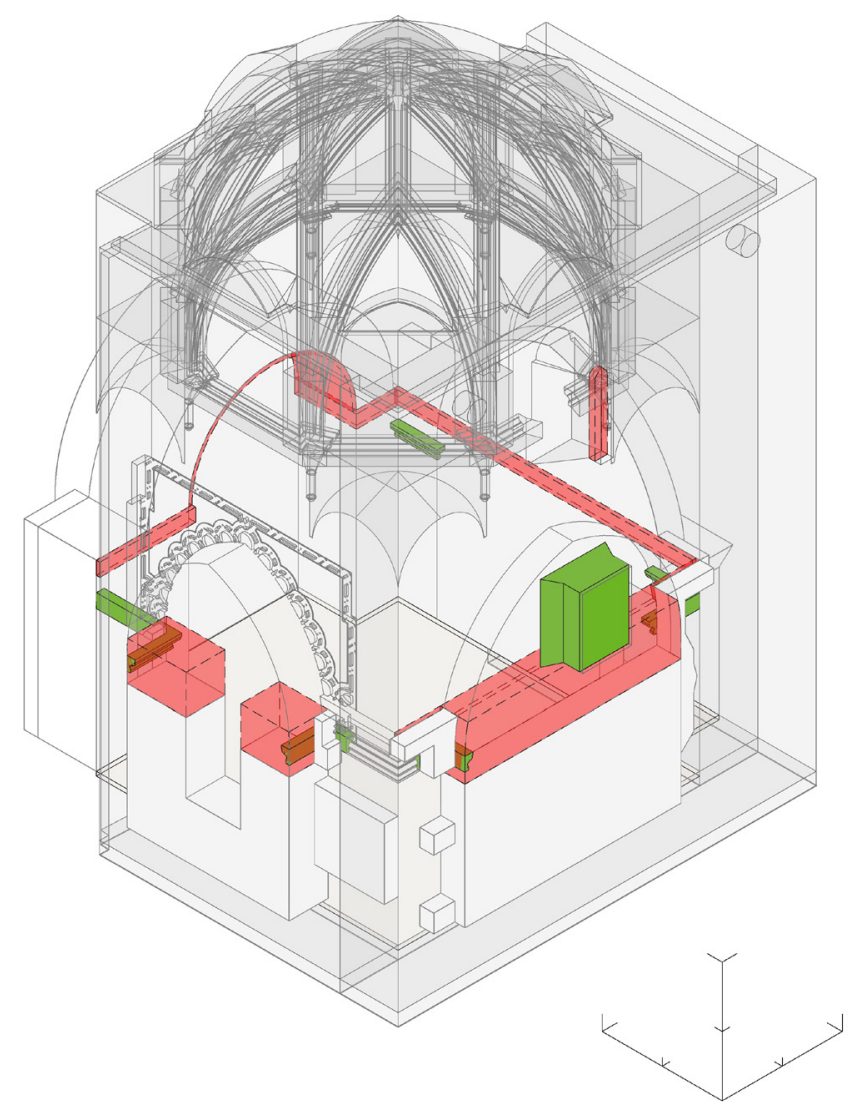

Figura 9. Elementos añadidos (verde) y eliminados (rojo) en la última restauración (2015-2016). Fuente: Elaboración propia.

trucción del modelo. A partir de un modelado genérico y básico de la iglesia avanzamos en su desarrollo en un ámbito más concreto, la capilla, que ha quedado asociado al anterior, incluyendo las fases principales de su secuencia evolutiva.

En este contexto, el uso de un modelo digital de información nos ha ofrecido ventajas fundamentales en los procesos de registro y gestión de la información. por un lado, la posibilidad de contar con una herramienta que aglutina la información completa de procesos - una intervención arqueológica o arquitectónica- que normalmente quedan ocultos o desaparecen tras su finalización. En el modelo digital no solo se dibuja un ente gráfico tridimensional, sino paramétrico, esto es, capaz de contener información asociada y relacionada por diversos parámetros que son familiares a las disciplinas arqueológica y arquitectónica: topológico, material, tipológico y cronológico (Fig. 10).

Por otro lado, el modelo supera el carácter finalista de representación de la realidad que reconocemos tradi- 
cionalmente, para convertirse en un medio interactivo y actualizable que puede formar parte de las estrategias de intervención.

Por último, las diversas visualizaciones que podamos hacer de él, tanto de manera estática eligiendo vistas convencionales, fragmentadas, como dinámicas moviéndolos en la pantalla, permite observar una dimensión-la espacial-que en muchas ocasiones está ausente de las proyecciones habituales usadas en arqueología y arquitectura.

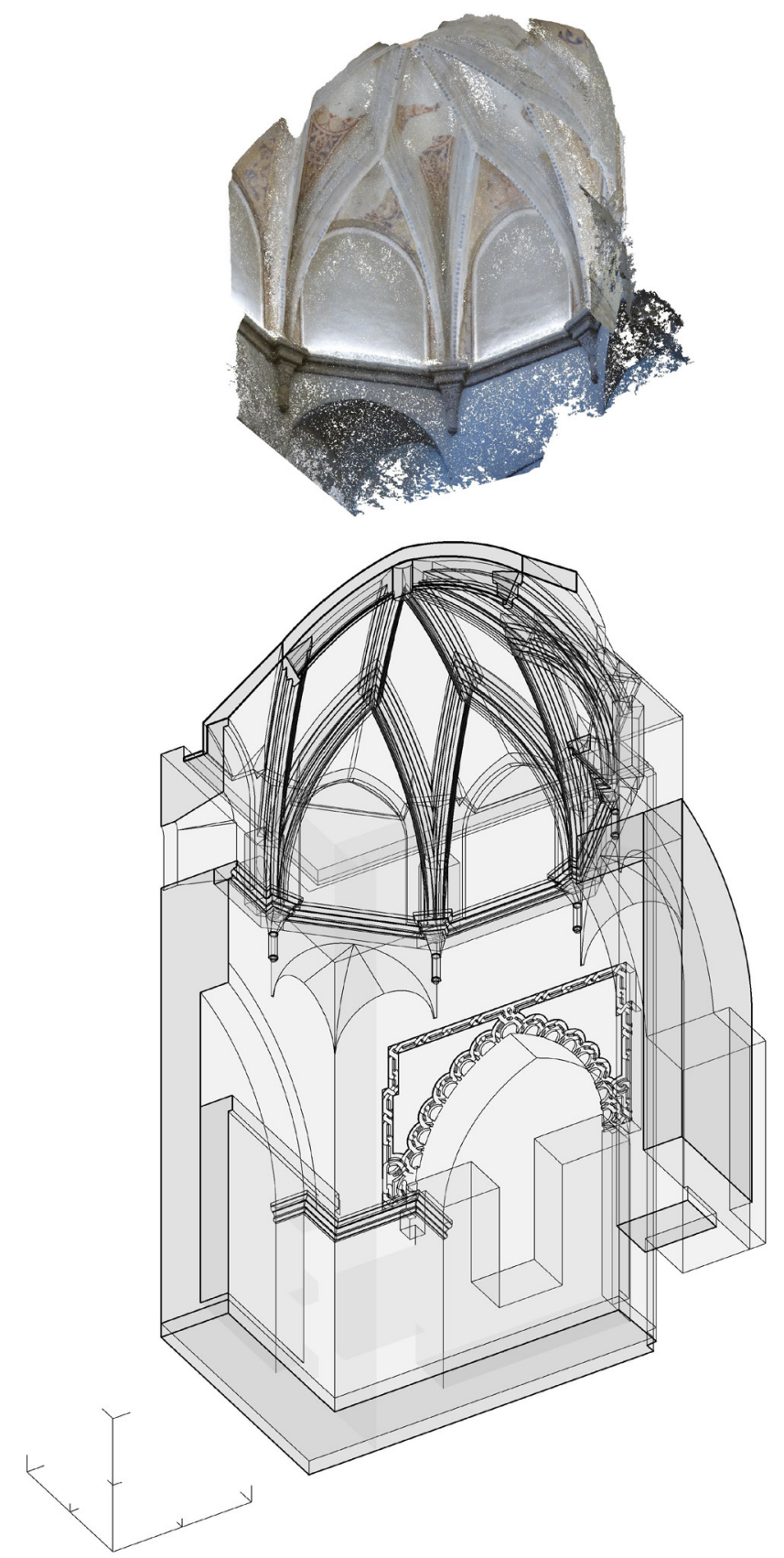

Figura 10. Nube de puntos de la fotogrametría de la bóveda tras la última restauración (2015-2016). Fuente: Elaboración propia.

\section{BIBLIOGRAFÍA}

Álvarez Luna, A., Guerrero Vega, J. M. y Romero Bejarano, M. 2003: La intervención en el Patrimonio. El caso de las iglesias jerezanas (1800-2000). Ayuntamiento de Jerez, Jerez.

Angulo Fornos, R. y Castellano Román, M. 2020: "HBIM as Support of Preventive Conservation Actions in Heritage Architecture. Experience of the Renaissance Quadrant Façade of the Cathedral of Seville", Applied Science, 10 (7), 2428. https://doi.org/10.3390/app10072428

Armisen Fernández, A. (coord.) 2018: BIM aplicado al Patrimonio Cultural. Documento 14. Building SMART Spanish Chapter, Madrid.

Azkarate, A., Cámara, L., Lasagabaster, J. I. y Latorre, P. 2001: Catedral de Santa María, Vitoria-Gasteiz: plan director de restauración. Diputación Foral de Álava - Fundación Catedral Santa María, Vitoria-Gasteiz.

Banfi, F., Barazzetti, L., Previtali, M. y Roncoroni, F. 2017: "Historic BIM: A new repository for structural health monitoring", The International Archives of the Photogrammetry, Remote Sensing and Spatial Information Sciences, XLII-5/W1, pp. 269-274. https://doi.org/10.5194/isprs-archi ves-XLII-5-W1-269-2017

Brusaporci, S., Trizio, I., Ruggeri, G., Maiezza, P., Tata, A. y Giannangeli, A. 2018: “AHBIM per l'analisi stratigrafica dell'architettura storica", Restauro Archeologico, 26(1), pp. 112-131. https://doi.org/10.13128/RA-23463

Castellano Román M. y Pinto Puerto F. 2019: "HBIM oriented towards the master plan of the Charterhouse of Jerez (Cádiz, Spain)", The International Archives of the Photogrammetry, Remote Sensing and Spatial Information Sciences, XLII-2/W15, pp. 285-290. https://doi.org/10.5194/isprs-archi ves-XLII-2-W15-285-2019

Dore, C., Murphy, M., McCarthy, S., Brechin, F., Casidy, C., y Dirix, E. 2015: "Structural Simulations and Conservation Analysis - Historic Building Information Model (HBIM)", The International Archives of the Photogrammetry, Remote Sensing and Spatial Information Sciences, XL5/W4, pp. 351-357. https://doi.org/10.5194/isprsarchives-XL-5-W4-351-2015

Dore C. y Murphy M. 2017: "Current state of the art historic building information modelling", International Archives of the Photogrammetry, Remote Sensing and Spatial Information Sciences, XLII-2/W5, pp. 185-192. https://doi.org/10.5194/isprs-archives-XLII-2-W5-185-2017

González Pérez, C. 2018: Information Modelling for Archaeology and Anthropology: Software Engineering Principles for Cultural Heritage. Springer, Cham.

Guerrero Vega, J. M. 2019: Espacio y construcción en la arquitectura religiosa medieval de Jerez de la Frontera (s. XIII-XV). Editorial Universidad de Sevilla, Sevilla.

Guerrero Vega, J. M., Pinto Puerto, F. y Mora Vicente, G. 2019: “Trabajos previos y paralelos integrados en el proyecto de restauración de la capilla de los Tocino (s. XV) en la iglesia de San Juan de los Caballeros de Jerez de la Frontera", Arqueología de la Arquitectura, 16: e087. https://doi. org/10.3989/arq.arqt.2019.009

Guerrero Vega, J. M., Mora Vicente, G. y Pinto Puerto, F. 2020: “Application of a BIM digital model for the representation of the constructive evolution of the apse of the church of San Juan de los Caballeros de Jerez de la Frontera", en P. Ortiz Calderón, F. Pinto Puerto, Ph. Verhagen y A. J. Prieto (eds.), Science and Digital Technology for Cultural Heritage, pp. 128-132. CRC Press, London.

Jácome González, J. y Antón Portillo, J. 2007: "La Capilla de la Jura, de San Juan de los Caballeros de Jerez de la Frontera: entre la épica y la realidad histórica", Revista de Historia de Jerez, 13, pp. 183-211.

Jordan-Palomar, I., Tzortzopoulos, P., García-Valldecabres, J. y Pellicer, E. 2018: "Protocol to Manage Heritage-Building Interventions Using Heritage Building Information Modelling (HBIM)", Sustainability, 10, 908, pp. 1-19. https://doi.org/10.3390/su10040908

Logothetis S., Delinasiou A. y Stylianidis E. 2015: "Building information modelling for cultural heritage: A review", ISPRS Annals of the Photogrammetry, Remote Sensing and Spatial Information Sciences, 2, 5W3: 177-183. https://doi.org/10.5194/isprsannals-II-5-W3-177-2015

López Vargas-Machuca, F. 2014: "Entre la tradición castellana y la herencia Andalusí. La arquitectura religiosa en Jerez de la Frontera desde la con- 
quista cristiana hasta la irrupción del tardogótico (1264-1464)", en Limes Fidei, 750 años de cristianismo en Jerez, pp. 65-99. Diócesis de Asidonia-Jerez, Jerez.

Mora Vicente, G. M. y Guerrero Vega, J. M. 2015: “Traza y proceso constructivo de la capilla de la Jura de Jerez de la Frontera", en Actas del Noveno Congreso Nacional y Primer Congreso Internacional Hispanoamericano de Historia de la Construcción. Segovia, 13-17 de octubre de 2015, 2, pp. 1121-1131. Instituto Juan de Herrera, Madrid.

Oreni, D., Brumana, R., Georgopoulos, A., y Cuca, B. 2013: "HBIM for conservation and management of built heritage: Towards a library of vaults and wooden bean floors", ISPRS Annals of photogrammetry, remote sensing and spatial information sciences, II-5/W1, pp. 215-221. https://doi. org/10.5194/isprsannals-II-5-W1-215-2013

Pinto Puerto, F. y Guerrero Vega, J. M. 2013: "Imagen y modelo en la investigación del patrimonio arquitectónico", Virtual Archaeology Review, 4, 8, pp. 135-139. https://doi.org/10.4995/var.2013.4346

Pocobelli, D. P., Boehm, J., Bryan, P., Still, J. y GrauBové, J. 2018a: "BIM for heritage science: a review", Heritage Science, 6, 30. https://doi. org/10.1186/s40494-018-0191-4
Pocobelli, D. P., Boehm, J., Bryan, P., Still, J. y Grau-Bové, J. 2018b: “Building Information Models for monitoring and simulation data in heritage buildings", The International Archives of the Photogrammetry, Remote Sensing and Spatial Information Sciences, XLII-2, pp. 909-916. https:// doi.org/10.5194/isprs-archives-XLII-2-909-2018

Quattrini, R., Pierdicca, R. y Morbidoni, C. 2017. "Knowledge-based data enrichment for HBIM: exploring highquality models using the semantic-web", Journal of Cultural Heritage, 8, pp. 129-139. https:// doi.org/10.1016/j.culher.2017.05.004

Scianna, A., Serlorenzi, M., Gristina, S., Filippi, M. y Paliaga, S. 2015: "Sperimentazione di tecniche BIM sull'archeologia romana: il caso delle strutture rinvenute all'interno della cripta della chiesa dei SS. Sergio e Bacco in Roma", Archeologia e Calcolatori, Supplemento 7, pp. 199-212.

Utrero, M. A., Murillo, J. L. y Martín-Talaverano, R. 2016: "Virtual models for archaeological research and 2.0 dissemination: The early medieval church of San Cebrian de Mazote (Spain)", Scientific Research and Information Technology, 6 (2), pp. 93-108. http://dx.doi.org/10.2423/ i22394303v6n2p93 